\title{
Silicon, Silica and Silicone in Kentucky
}

\author{
Michael J. Owen
}

Received: 7 March 2014 / Accepted: 18 April 2014 / Published online: 12 May 2014

(C) Springer Science+Business Media Dordrecht 2014

Many states in the USA nominate a state mineral or rock to draw attention to their natural resources and to promote interest in tourism. Kentucky has both a state mineral and a state rock. The state mineral is coal but the state rock is the Kentucky agate which is a microscopically crystalline form of quartz, the oxide of our favorite element. An example of a Kentucky agate is shown in Fig. 1. Purists will quibble that the state's rock is really a mineral and the state mineral is better described as a rock but we are content that silicon has been featured in this way.

There is also an interesting connection between coal and silicon in that specialty metallurgical coal is a key ingredient in the production of silicon metal. The Blue Gem coal seam in southern Kentucky and northeastern Tennessee is a major source of suitable high quality coal for the silicon industry and is controlled by Alden Resources LLC of Corbin, Kentucky. The company is a subsidiary of Global Specialty Metals Inc. Silica sand has also been mined in numerous locations in Kentucky, presumably including the almost-forgotten eponymous settlement of Silica in Carter County, Kentucky. An increasing number of sand mines are operational again nowadays, probably a reflection of sand use in hydraulic fracking.

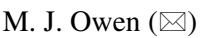

Michigan Molecular Institute, 1910 West Saint Andrews Road,

Midland, MI 48640-2696 USA

e-mail: michaelowen01@ chartermi.net
Two other instances of silicon significance in Kentucky today that are worthy of mention are Silrec Corporation and the Silicon Hollow Association. The former produces silicon wafers for the semiconductor and solar industries and others. It was founded in 1986 in California and moved its headquarters to Lexington, Kentucky in 2002. As might be guessed from its name, the company is notable for its pioneering recycling of scrap silicon material. The Silicon Hollow Association is a network of IT and computing science firms based in eastern and south central Kentucky with the aim of providing clients with outstanding telecommunication services. Among its founders are Innovation and Commercialization Centers at Eastern Kentucky University, Morehead State University and Ashland Community and Technical College.

Silicones have featured strongly in the Kentucky economy for over half a century. In the 1960's Dow Corning Corporation, the leading global producer of silicones, established two plants in Kentucky, one at Elizabethtown and one at Carrollton. The Elizabethtown facility came first. It has been part of the Elizabethtown community since 1963. It produces sealants, caulks and coatings for the construction and other industries.

The Carrollton facility alongside the Ohio River in Carroll County is one of the largest primary silicone-producing plants in the world. It has produced silicone fluids, blends, emulsions and intermediate materials used in many of Dow Corning's 7,000 products since 1967 . As silane intermediates, such as dimethyldichlorosilane, are produced industrially by the Rochow-Muller direct process between methyl chloride and silicon metal, it is conceivable that some of them may well have been obtained with the aid of 


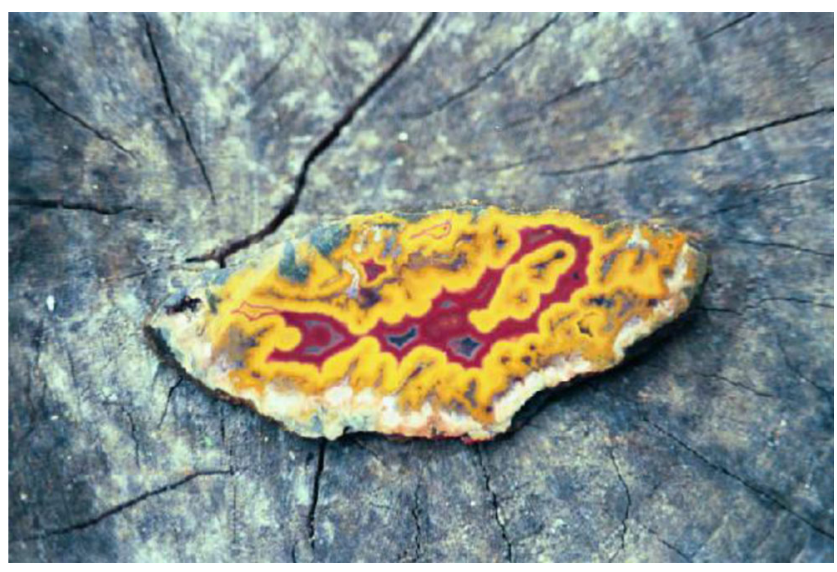

Fig. 1 A Kentucky agate, reproduced with permission of the Kentucky Geological Survey. Their web-site (www.uky.edu/KGS/ rocksmn/kentuckyagate.htm) has many more examples
Kentucky's Blue Gem coal. Perhaps silicone should be designated the state's official polymer?

The late Jim Klingler, who was a member of the original plant staff and subsequently plant manager, had a considerable collection of Native American artifacts such as rudimentary tools and arrowheads from the site and nearby, some of which must have been made of flint. It is thoughtprovoking to imagine that a silicon-based industry greatly preceded the arrival of Dow Corning at Carrollton. There are plans to build a Kentucky Center for Native American Arts and Culture to house such artifacts in General Butler State Resort Park, a few miles from the Dow Corning site. This collection of Native American artifacts will show the presence of a silicon-based industry in Kentucky that not only preceded the silicone industry but also any European settlement. 